\title{
One-way avoidance acquisition as a function of intertrial interval and relative time in "safe" area
}

\author{
FRANK A. HOLLOWAY \\ University of Oklahoma Health Sciences Center, Oklahoma City, Oklahoma \\ and \\ MORRIE BAUM \\ Rensselaer Polytechnic Institute, Troy, New York
}

\begin{abstract}
The rate of acquisition for a one-way, "jump-up" active avoidance response was positively correlated with the proportion of the intertrial interval (ITI) spent in the "safe" region of the avoidance chamber, regardless of the length of the ITI. However, rats permitted only brief periods of removal from noxious stimuli (the grid floor) still learned the avoidance response, though less rapidly. This difference was discussed in terms of relief/relaxation following each response and a possible "flooding" (response prevention) effect on each trial.
\end{abstract}

The effect of the intertrial interval (ITI) on avoidance acquisition has been infrequently examined. Earlier experimenters, utilizing the shuttlebox, typically found more rapid acquisition with longer ITIs of up to 1 or $2 \mathrm{~min}$ (e.g., Levine \& England, 1960; Murphy \& Miller, 1956). Brush (1962) found a U-shaped function with the rate of avoidance acquisition increasing with increases in ITI of up to $5 \mathrm{~min}$ but decreasing with further increases in the ITI.

Utilizing one-way avoidance procedures, Denny and Weisman (1964) trained rats in a "jump-out" avoidance task and found that with a constant 230 -sec ITI, the rate of avoidance acquisition generally increased with increases in time spent in the "safe" region of the jump-out box. Bolles and Nelson (1975) found that one-way avoidance performance (jump-up or running) progressively declined as the ITI increased from 10 to $180 \mathrm{~min}$. Reynierse, Weisman, and Denny (1963) found decrements in one-way avoidance performance when the rat was confined to the shock area for most of the 2-min ITI. Furthermore, Holloway and Wansley (1974) found that one-way avoidance acquisition with a constant 15-min "safe" platform period decreased monotonically with increasing periods on the grid floor ranging from 3 to $60 \mathrm{sec}$.

Few of the studies discussed thus far have varied both the ITI and the relative time spent in the "safe" and "dangerous" regions of the avoidance chamber. Most of the studies of Denny and colleagues (Delprato \& Denny, 1970; Denny \& Weisman, 1964; Reynierse et al., 1963) included only a single ITI. In the present experiment, we sought to examine one-way active avoidance acquisition

Requests for reprints should be addressed to Frank A. Holloway, University of Oklahoma Health Sciences Center, Research Building 306-R, P.O. Box 26901, Oklahoma City, OK 73190-3000. at several ITIs, with a relatively small percentage of each ITI spent either in the safe or in shocked regions of the avoidance apparatus.

\section{METHOD}

\section{Subjects}

The subjects for this experiment were 80 male albino rats (Sasco, Inc.), ranging in weight from 329 to $434 \mathrm{~g}$ at the beginning of the experiment. All subjects had ad-lib access to food and water and were maintained on a 12:12-h light:dark schedule (lights on at $0800 \mathrm{~h}$ ).

\section{Experimental Design}

Eighty subjects were randomly assigned to one of eight active avoidance conditions $(n /$ group $=10)$ defined by four intertrial intervals (ITI $=18,75,132$, and $249 \mathrm{sec}$ ) and by two procedural conditions (time on grid floor [TGF] of $3 \mathrm{sec}$ and time on platform [TOP] of $3 \mathrm{sec}$ ). The ITI equaled the TOP plus TGF intervals.

\section{Apparatus}

The one-way, step-up active avoidance apparatus, described in detail elsewhere (Holloway, 1972), was similar to that developed by Baum (1965) and redescribed pictorially by Lapoint and Baum (1987).

Briefly, the apparatus was a Plexiglas box $(50.5 \mathrm{~cm}$ high, $38.1 \mathrm{~cm}$ square; two sides were black and two sides clear), with a stainless steel grid floor (rod diameter $=6.2 \mathrm{~mm}$ ). On one of the black walls, a slot located $15.2 \mathrm{~cm}$ above the grid floor permitted introduction of a platform $(12.7 \mathrm{~cm}$ square, with $1.5-\mathrm{mm}$ brass rods on the surface) into the chamber. When the platform was retracted, a Plexiglas flap covered the slot, preventing the rat from reaching the platform. Electromechanical operation of the platform required $1.4 \mathrm{sec}$. Two parallel photocells were located $3.8 \mathrm{~cm}$ above the platform $(3.8 \mathrm{~cm}$ off the midline). The rat's simultaneous depression of the platform microswitch and activation of one of the two photocells defined an avoidance or escape response. Shock could be delivered to the grid floor only via a BRS constant wattage shock generator-scrambler (SGS-001). The entire apparatus was housed in a dimly lit, sound-attenuated room.

\section{Procedure}

Without any prior adaptation to the apparatus or prior handling, each rat was placed on the grid floor with the platform retracted. The first trial began $30 \mathrm{sec}$ later with the introduction of the platform into the 
chamber, followed $10 \mathrm{sec}$ later by $0.1 \mathrm{~W}$ of shock delivered to the grid floor (maximum shock duration $=20 \mathrm{sec}$ ). (The shock generator delivered a maximum of $400 \mathrm{~V} \mathrm{dc}$ with constant power output between subject resistances of 20 and $100 \mathrm{k} \Omega$, which would produce a range of currents from 1.00 to $1.12 \mathrm{~mA}$.) The warning stimulus from insertion of the platform had visual, auditory, and vibratory components.

Once the animal climbed onto the platform, the shock was terminated, and the platform remained out for an additional period (variable TOP). At the end of the latter period, the platform was retracted, allowing the rat to gently drop to the grid floor. If no response was made, the platform was retracted at the end of the maximum shock time. At the end of one of the TGFs, the platform was again introduced for Trial 2, and so on, until the rat met a criterion of four consecutive conditioned avoidance responses (CAR). A CAR occurred when the rat climbed onto the platform prior to the shock; an escape response occurred when a rat climbed onto the platform after the shock onset. All subjects were run between the hours of 1000 and 1600 .

\section{RESULTS}

Two-way analyses of variance were performed on the following measures: $\log$ trials to criterion, $\log$ shocks to criterion, and \%CAR. The log transformations were necessitated by significant $F$-max tests on the criterion measures.

The trials-to-criterion (TTC) and shocks-to-criterion (STC) acquisition data are presented in Figure 1. Groups with a brief TOP took significantly more trials $[F(1,72)$ $=197.33, p<.01]$ and more shocks $[F(1,72)=142.75$, $p<.01]$ to reach criterion than did groups with the brief TGF. There was also a significant variance across ITIs $[\mathrm{TTC}, F(3,72)=5.58, p<.01 ; \mathrm{STC}, F(3,72)=3.86$,

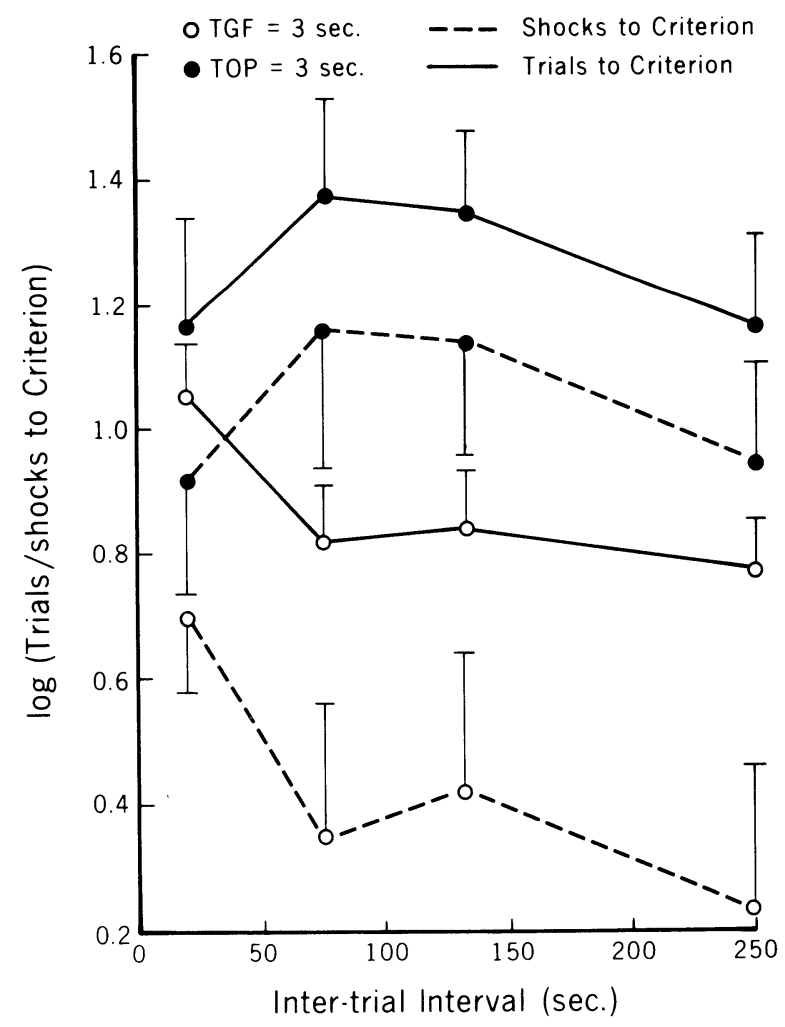

Figure 1. Avoidance acquisition as a function of length of intertrial interval (means and $S E$ ).

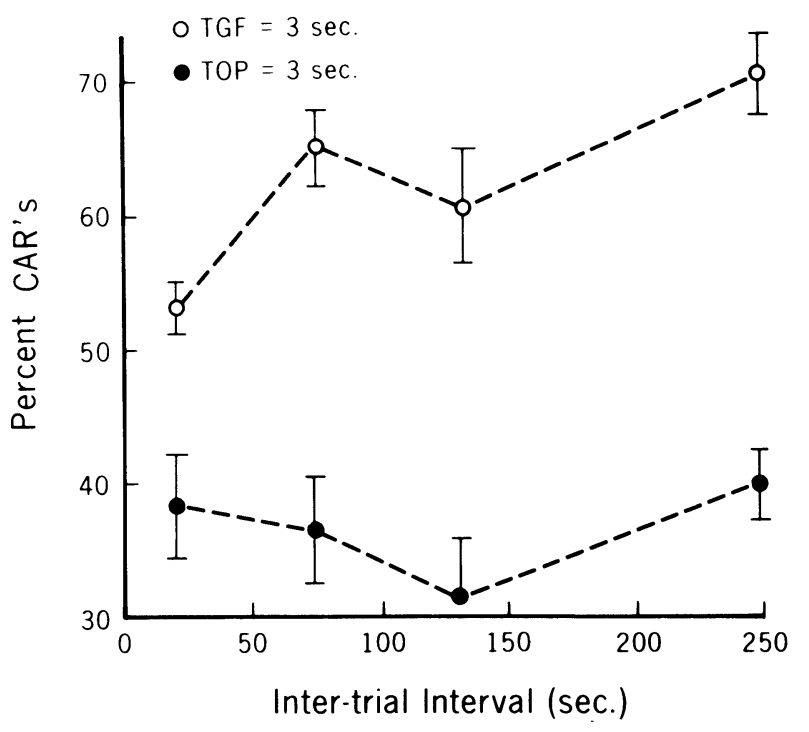

Figure 2. Percentage of avoidance responses as a function of intertrial interval (means and $S E$ ).

$p<.05]$ and significant interaction between ITI and TOP-TGF conditions [TTC, $F(3,72)=11.89, p<.01$; STC, $F(3,72)=4.68, p<.01]$. Duncan multiple range tests (Duncan, 1955) indicated that among the groups spending only $3 \mathrm{sec}$ on the platform, those with ITIs of 75 or $132 \mathrm{sec}$ took significantly more trials (but not more shocks) to reach criterion $(p<.01)$ than did those with ITIs of 10 or $249 \mathrm{sec}$. Trend analyses indicated a significant quadratic effect across ITIs in the groups with a TOP of $3 \mathrm{sec}$ [TTC, $F(1,72)=22.92, p<.01$; STC, $F(1,72)$ $=9.12, p<.01]$. Among the groups with a TGF of $3 \mathrm{sec}$, the group with the ITI of $18 \mathrm{sec}$ took significantly more trials and shocks to reach criterion $(p<.01)$ relative to groups with ITIs of 75, 132, or $249 \mathrm{sec}$ (the latter groups did not differ among one another). Trend analyses on the latter data indicated a significant linear component across ITIs in both the TTC $[F(1,72)=21.95$, $p<.01]$ and STC $[F(1,72)=16.50, p<.01]$, and a significant cubic component in the STC measure $[F(1,72)$ $=4.48, p<.05]$.

The \%CAR acquisition data are presented in Figure 2. A significant difference among ITIs $[F(3,72)=105.26$, $p<.01]$ and between the TGF and TOP conditions $[F(1,72)=3.36, p<.01]$ was obtained, but the interaction was not significant. Simple effect analyses indicated that the groups with a TOP of $3 \mathrm{sec}$ had significantly lower \%CAR than did groups with a TGF of $3 \mathrm{sec}$, regardless of the ITI (all $p s<.01$ ). However, the ITI simple effect was only significant $(p<.01)$ for all groups with the TGF of $3 \mathrm{sec}$. Among the latter groups, those with ITIs of 249 and $75 \mathrm{sec}$ had significantly higher \%CAR than did the group with the ITI of $18 \mathrm{sec}$. The latter groups also displayed a significant linear trend across ITIs $[F(1,72)=9.61, p<.01]$.

These data indicate that with brief exposures to the grid floor (TGF $=3 \mathrm{sec}$ ), acquisition performance displays a linear improvement with increasing ITIs. Stated 
another way, as the proportion of time spent on the "safe" platform increases relative to the ITI, performance improves.

\section{DISCUSSION}

The results of the present experiment demonstrate that avoidance acquisition is superior as more of the ITI is spent on the platform (vs. time spent on the grid). This is to some extent consistent with Denny's (1971) relaxation theory, which stresses the reinforcing effects of the opportunity to relax or find relief after each avoidance/escape response.

Furthermore, for the rats spending substantial amounts of time on the grid during each ITI, a "flooding," or response-prevention, effect may be coming into play. Flooding refers to detaining the rat in the presence of the fear stimuli (CS) without shock, and has been shown to hasten avoidance extinction (see Baum, 1970, 1976 for reviews). Being on the grid floor is part of the CS (as a context) for all rats in this study. Time on grid during ITIs can lead to Pavlovian extinction of fear after each trial, so that the response is weakened and acquisition slowed (until the rat's responding comes more under the control of the platform insertion part of the CS). Gordon ahnd Baum (1987) have recently reported that flooding or response-prevention durations of as little as $30 \mathrm{sec}$ (total duration) can readily disrupt avoidance performance in rats.

The present results indirectly address the issue raised by Masterson, Crawford, and Bartter (1978) of why rats learn flight (one-way) responses more rapidly than other types of avoidance responses. These authors acknowledged that prolonged "escape from shock-box cues" contributes to the rapidity of one-way avoidance acquisition, but they demonstrated that relatively rapid acquisition still can occur with only brief periods of escape from shock-box cues. Similarly, in the present study, we found that rats permitted $3 \mathrm{sec}$ on the "safe" platform and spending the remainder of the 249-sec ITI on the grid floor still met the four successive CAR criterion relatively quickly (an average of 15.5 trials). Bolles and Nelson (1975) reported that even at an ITI of $1 \mathrm{~h}$, rats spending only a brief preresponse period in the shocked part of the chamber and the rest in the "safe" area displayed relatively good performance $[\bar{X}$ $(\%$ CAR $)=58$ ]. However, the present study indicates that when only a brief time on the platform is permitted, acquisition rate shows a quadratic relation to increase in ITI, with the poorest performance occurring with an ITI of $75 \mathrm{sec}$. In the Bolles and Nelson (1975) study, rats that spent all of the 1-h ITI in the shocked area displayed exceptionally poor performance $[\bar{X}(\% \mathrm{CAR})=12.5]$. In the present study, the mean \%CAR of rats spending a brief time in the shock area increased linearly across ITI, whereas the mean \%CAR of rats spending a brief time in the "safe" area remained relatively low (between $30 \%$ and $40 \%$ ). Since an automated apparatus was utilized in the present study, no betweentrial handling of the rats was required. In most other one-way avoidance studies, such handling has occurred.

\section{REFERENCES}

BAuM, M. (1965). An automated apparatus for the avoidance training of rats. Psychological Reports, 16, 1205-1211.

BAUM, M. (1970). Extinction of avoidance responding through response prevention (flooding). Psychological Bulletin, 74, 276-284.

BAUM, M. (1976). Instrumental learning: Comparative studies. In M. P. Feldman \& A. Broadhurst (Eds.), Theoretical and experimental bases of the behavior therapies (pp. 113-131). New York: Wiley.

Bolles, R. C., \& NeLSON, K. (1975). The role of intertrial interval in the learning of two simple avoidance tasks. Animal Learning \& Behavior, 3, 157-160.

BRUSH, F. R. (1962). The effects of intertrial interval on avoidance learning in the rat. Journal of Comparative \& Physiological Psychology, $55,888-892$.

DelPrato, D. J., \& Denny, M. R. (1970). Passive avoidance as a function of duration of nonshock confinement. Learning \& Motivation, 1, 44-52.

DeNNy, M. R. (1971). Relaxation theory and experiments. In F. R. Brush (Ed.), Aversive conditioning and learning (pp. 235-295). New York: Academic Press.

DenNy, M. R., \& Weisman, R. G. (1964). Avoidance behavior as a function of length of nonshock confinement. Journal of Comparative \& Physiological Psychology, 58, 252-257.

Duncan, D. B. (1955). Multiple range and multiple $F$ tests. Biometrics, 11, 1-42.

Gordon, A., \& BaUm, M. (1987). Shuttlebox avoidance in rats and response prevention (flooding): Persistence of fear following reduced instrumental responding. Journal of General Psychology, 114, 263-272.

Holloway, F. A. (1972). State-dependent effects of ethanol on active and passive avoidance learning. Psychopharmacologia, 25, 238-261.

Holloway, F. A., \& WANSLEY, R. A. (1974). Motivational parameters in ethanol-induced state-dependent dissociation of avoidance learning. Physiological Psychology, 2, 71-74.

LAPOINT, A., \& BAUM, M. (1987). Description of spontaneous behavior of individual rats undergoing avoidance-response-prevention (flooding). Psychological Reports, 61, 879-885.

Levine, S., \& ENGLAND, S. J. (1960). Temporal factors in avoidance conditioning. Journal of Comparative \& Physiological Psychology, 53, 282-283.

Masterson, F. A., Crawford, M., \& Bartter, W. D. (1978). Brief escape from a dangerous place: The role of reinforcement in the rat's one-way avoidance acquisition. Learning \& Motivation, 9, 141-163.

MurPhY, J. V., \& Miller, R. E. (1956). Spaced and massed practice with a methodological consideration of avoidance conditioning. Journal of Experimental Psychology, 52, 77-81.

Reynierse, J. H., Weisman, R. G., \& Denny, M. R. (1963). Shock compartment confinement during the intertrial interval in avoidance learning. Psychological Record, 13, 403-406. 